\title{
Prólogo a la edición española
}

Cuando el Consejo de Europa sugirió la conveniencia de preparar una edición española del THESAURUS EUDISED MULTILINGÜE, el proyecto fue acogido por el Ministerio español de Educación y Ciencia con verdadero calor. Canalizándolo a través de la Dirección General de Archivos y Bibliotecas y del entonces Centro Nacional de Investigaciones para el Desarrollo de la Educación, tras una reunión celebrada en Octubre de 1.973 en Toledo, quedó constituído un equipo lo suficientemente pequeño a fin de poder trabajar con eficacia y lo suficientemente variado para aportar diferentes puntos de vista. Amalia Calvo Chalud, documentalista y bibliotecaria del Instituto Nacional de Ciencias de la Educación, Julio Ruiz Berrio, Profesor de Educación Comparada, David Torra Ferrer, Inspector General de Bibliotecas y, en último lugar, yo mismo que tengo como una de mis tareas profesionales la sistematización de los problemas educativos.

Apenas iniciados los trabajos, y cuando ya nos habíamos enfrentado con las dificultades que en él se entrañaban, contamos con la inapreciable ayuda de $\mathrm{M}$. Jean Viet con quien en unos días de apretado trabajo en el Instituto de Pedagogía concretamos los criterios que debían utilizarse para la puesta a punto de la edición española.

La más grave dificultad en la asimilación de los términos de un idioma a otro se halla en la casi imposibilidad de que las distintas significaciones de una palabra coincidan exactamente con las de la considerada equivalente en otra lengua, máxime cuando al sentido denotativo necesariamente se une el connotativo de cada expresión. Esta dificultad se salva en gran parte con la técnica y notación adoptadas para expresar las interrelaciones del vocabulario tal como se indica en la introducción. Por otra parte, el haber tenido a la mano los léxicos alemán, francés e inglés nos ha permitido afinar en la selección de la palabra o expresión española más adecuada para identificar cada concepto.

Esperamos que esta edición del THESAURUS EUDISED constituya un buen medio de trabajo en manos de los estudiosos de habla española, bien entendido que quienes lo usen pueden contribuir con su experiencia a hacer más útil este instrumento que, no importa repetirlo. habrá de irse 
VIII Prólogo a la edición española

acompasando en posibles sucesivas ediciones al desarrollo en el campo de la terminología pedagógica.

Víctor García Hoz

Director. Instituto de Pedagogía.

Consejo Superior de Investigaciones Cientificas, Madrid 